\title{
Correction to: Predator-based selection and the impact of edge sympatry on components of coral snake mimicry
}

\author{
Lauren Wilson $^{1}$ (D) George Lonsdale ${ }^{2}$. John David Curlis ${ }^{1,3} \cdot$ Elizabeth A. Hunter $^{1}$. \\ Christian L. Cox ${ }^{1,4}$
}

Published online: 21 February 2022

๑) Springer Nature Switzerland AG 2022

\section{Correction to: Evolutionary Ecology https://doi.org/10.1007/s10682-021-10143-8}

In the original publication of the article, the texts "Data will be deposited at Dryad upon acceptance", under Data availability section should be read as "Data available through Dryad at: https://doi.org/10.5061/dryad.pnvx0k6kv".

The original article has been corrected.

Publisher's Note Springer Nature remains neutral with regard to jurisdictional claims in published maps and institutional affiliations.

The original article can be found online at https://doi.org/10.1007/s10682-021-10143-8.

Lauren Wilson

laurenwilson25@gmail.com

George Lonsdale

georgelonsdale1@gmail.com

John David Curlis

curlisjd@umich.edu

Elizabeth A. Hunter

elizabethhunter@georgiasouthern.edu; ehunter1@vt.edu

Christian L. Cox

ccox@fiu.edu

1 Georgia Southern University, Statesboro, GA, USA

2 University of Plymouth, Plymouth, UK

3 University of Michigan, Ann Arbor, MI, USA

4 Florida International University, Miami, FL, USA 